
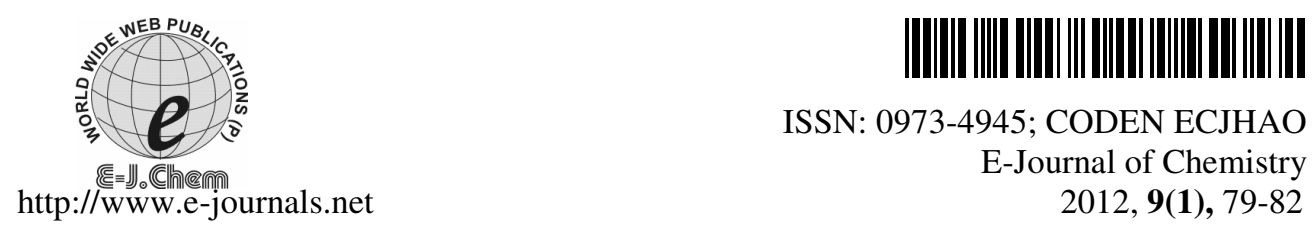

ISSN: 0973-4945; CODEN ECJHAO

E-Journal of Chemistry

2012, 9(1), 79-82

\title{
Determination of Lead in Saudi Arabian Imported Green Tea by ICP-MS
}

\author{
AHMED OTHMAN*, SEHAM AL-ANSI and MOHAMMED AL-TUFAIL \\ Toxicology and Bio-Analysis Section, \\ Department of Pathology and Laboratory Medicine, \\ MBC10, King Faisal Specialist Hospital \& Research Center, \\ P.O. Box 3345, Riyadh 11211, Saudi Arabia \\ aothman@kfshrc.edu.sa
}

Received 1 May 2011; Accepted 13 July 2011

\begin{abstract}
Lead $(\mathrm{Pb})$ in nine different Saudi Arabian imported green tea samples originated from China has been determined using inductively coupled plasma mass spectrometry (ICP-MS). Tea infusion and microwave acid digestion procedures are used for sample pre-treatment. The concentrations range of lead (total) in the analyzed green tea samples is $0.231-6.340 \mathrm{mg} / \mathrm{kg}$. The total concentration of lead released 3\% - 19\% into tea infusions with boiling water. The calculated average daily intakes of lead in tea infusions was low and within the bounds of safety $(\leq 0.009 \mathrm{mg} /$ day $)$.
\end{abstract}

Keywords: ICP-MS, Lead, Green tea, Infusion

\section{Introduction}

Tea is the most popular beverage in the world. It is made from the processed leaves of Camellia sinensis plants and originates from China. The three most popular types of tea (green, oolong, and black) are distinguished on the basis of degree of fermentation. The leaves of green tea are dried and roasted but not fermented for green tea product ${ }^{1}$. Many studies have concluded that tea has numerous beneficial effects on health including the prevention of many diseases such as certain types of cancer, Parkinson's diseases, myocardial infarction and coronary artery disease ${ }^{2,3}$.

The contaminations of tea by heavy metals may pose a serious threat to human, because they remain in environment and pass to food chain ${ }^{4}$. Lead $(\mathrm{Pb})$ is one of the most common environmental contaminants due to its wide use in petroleum, mining, paint and pigments, ceramics and weapons industries. Its accumulation in the body may cause several pathological states, including brain damage, kidney failure and serious developmental, learning and behavioral problems in children ${ }^{5-7}$. Therefore, lead content of tea has become public health issue. The concentration of lead in different tea leaves and tea infusion samples have been studied, but there is still not enough information on its allowable standard limits ${ }^{4,8}$. 
In the present study, lead has been determined in nine imported green tea samples using ICP-MS. Tea infusion and microwave acid digestion procedures were used for sample pretreatment. The data obtained will provide information on lead toxic levels in these samples when compared to U.S. Agency for Toxic Substances and Disease Register (ATSDR) daily average intake of lead by consumption of food, $\leq 0.009 \mathrm{mg} / \mathrm{day}^{10}$.

\section{Experimental}

PerkinElmer SCIEX Inductively coupled plasma mass spectrometer (ICP-MS), model ELAN 9000, with S10 auto-sampler, DELL pc with perkin elmer software system control, MDS SCIEX Canada, was used for the detection of lead, its operating conditions ${ }^{11,12}$ given in Table 1. Multiwave 3000 acid digestion system, Anton paar GmbH, Graz, Austria, Milli-Q academic, RiOs 8, water purification system ( $\geq 18.2 \mathrm{M} \Omega$ ), Millipore, France and Beckman Coulter, Allegra X-12 centrifuge, 3500 RPM, USA were used in this study.

Table 1. Instrumental operating conditions for ICP-MS

\begin{tabular}{cccc}
\hline Vacuum pressure (Torr) & $2.03 \mathrm{e}-005$ & Torch & Quartz \\
\hline RF power (Watts) & 1100 & Skimmer cone & Nickel \\
Nebulizer flow rate (L/min) & 0.84 & Sampler cone & Nickel \\
Lens voltage (Volts) & 7.5 & Nebulizer & Cross flow tip \\
Detector mode & Pulse & Alumina injector & 2.0 mm i.d. \\
\hline
\end{tabular}

\section{Reagents, standards and samples}

Nine different imported Chinese green tea samples were collected from Saudi Arabian markets for the analysis. Lead standard solution $(1000 \mu \mathrm{g} / \mathrm{mL})$ supplied by PerkinElmer was used for preparation of standard calibration curve. Rhodium standard solution $(1000 \mu \mathrm{g} / \mathrm{mL})$ supplied by PerkinElmer was used for preparation of internal standard. FAPAS soya flour quality control test material, T0770 and soya flour external proficiency testing samples, T07109, Food \& Environment Research Agency (fera), York, U.K, were used for precision and accuracy of the method. Distilled and de-ionized water was obtained using Milli-Q academic (RiOs 8), Millipore, France and nitric acid 69.0-70.0 \% for trace element analysis from Baker, Inc., NJ, USA, were used throughout.

\section{Procedures}

All standards were made by appropriate dilution of $1000 \mathrm{mg} / \mathrm{L}$ stock solution of lead with $1.0 \%$ (v/v) $\mathrm{HNO}_{3}$. A series of lead standards in $1.0 \%(\mathrm{v} / \mathrm{v}) \mathrm{HNO}_{3}$ was prepared to contain lead at 0 , 10,50 and $100 \mu \mathrm{g} / \mathrm{L}$. All quality control, external proficiency testing, green tea samples were digested into multi-wave digestion system using $25 \%$ (v/v) nitric acid. Infusion was prepared from $2.0 \mathrm{~g}$ of tea sample in $100 \mathrm{~mL}$ boiled distilled and de-ionized water. Matrix matched calibration standards, quality control, external proficiency testing and green tea samples were prepared by adding $200 \mu \mathrm{L}$ of each into $10 \mathrm{~mL}$ diluent (diluent was prepared by adding $10 \mu \mathrm{L}$ of rhodium as an internal standard into $1 \mathrm{~L}$ of $\left.1.0 \%(\mathrm{v} / \mathrm{v}) \mathrm{HNO}_{3}\right)$. Reagent blank was prepared similarly by adding $200 \mu \mathrm{L}$ of distilled de-ionized water. Blank, standards and samples were mixed, centrifuged and carried out in the ICP-MS auto-sampler for measurements. Data acquisition parameters were, peak hopping using mass $208 \mathrm{amu}, 50 \mathrm{~ms}$ dwell time, 20 sweeps per reading, 1 reading per replicate and 3 replicates. The total analysis time per solutions was $40 \mathrm{~s}$.

\section{Results and Discussion}

The analytical standard calibration curve obtained for lead gave correlation coefficient values better than 0.9999 in all cases. The linearity of the method in an aqueous matrix was obtained 
using twice the high working standard, $(200 \mu \mathrm{g} / \mathrm{L})$ and diluted serially six times and run against the analytical curve giving correlation coefficient of 0.9999 over $6.3-200.0 \mu \mathrm{g} / \mathrm{L}$ range. Similarly, detection limits were obtained with a serial dilution of standard one $(10 \mu \mathrm{g} / \mathrm{L})$ by six times $(0.3-10.0 \mu \mathrm{g} / \mathrm{L})$ giving a correlation coefficient of 0.9999 and limit of detection of $0.3 \mu \mathrm{g} / \mathrm{L}$, limit of quantification of $1.0 \mu \mathrm{g} / \mathrm{L}$ and an analytical measurement range of $1.0-200.0 \mu \mathrm{g} / \mathrm{L}$.

The precision of the method was tested using FAPAS soya flour quality control sample, T0770. The Inter-day precision data for lead obtained from twenty determinations are in agreement with $\pm 17 \%$ correlation of variation $(\mathrm{CV})$ value. The mean concentration of lead, standard deviation and satisfactory range are shown in Table 2. For accuracy, one external proficiency testing, FAPAS, soya flour, T07130, was analyzed, and three tea samples were analyzed by both KFSHRC, Saudi Arabia and Food and Environment Research Agency (fera), UK for comparison. The percent difference values range from 0 - 13 as shown in Table 3.

Table 2. Inter-day precision data for lead

\begin{tabular}{cccccc}
\hline $\begin{array}{c}\text { Quality } \\
\text { Control }\end{array}$ & $\mathrm{n}^{\mathrm{a}}$ & $\begin{array}{c}\text { Mean, } \\
\mathrm{mg} / \mathrm{kg}\end{array}$ & $\begin{array}{c}\mathrm{SD}, \\
\mathrm{mg} / \mathrm{kg}\end{array}$ & $\begin{array}{c}\text { Satisfactory } \\
\text { range, } \mathrm{mg} / \mathrm{kg}\end{array}$ & $\mathrm{CV}, \%$ \\
\hline FAPAS $^{\mathrm{b}}$ & 20 & 0.428 & 0.078 & $0.273-0.584$ & 17 \\
\hline
\end{tabular}

${ }^{a}$ Number of readings. ${ }^{b}$ FAPAS Soya flour Quality control test material, T0770, fera, U.K.

Table 3. Comparison of lead results obtained by KFSHRC and fera laboratories

\begin{tabular}{cccc}
\hline Sample & KFSHRC $^{\mathrm{a}}, \mathrm{mg} / \mathrm{kg}$ & fera $^{\mathrm{b}}, \mathrm{mg} / \mathrm{kg}$ & \% diff. from fera \\
\hline Tea 1 & 4.46 & 4.24 & 5 \\
Tea 2 & 0.27 & 0.27 & 0 \\
Tea 3 & 0.25 & 0.25 & 0 \\
Proficiency testing $^{\mathrm{c}}$ & 0.328 & 0.291 & 13 \\
\hline
\end{tabular}

${ }^{a}$ King Faisal Specialist Hospital \& Research Center ,KSA. ${ }^{b}$ Food \& Environment Research Agency, $U K .{ }^{c} P T$, FAPAS, Soya Flour, T07130, fera, UK.

The concentration range for lead in the nine different imported Chinese green tea samples is $0.231-6.340 \mathrm{mg} / \mathrm{kg}$ with acid digestion and $0.041-0.265 \mathrm{mg} / \mathrm{kg}$ using the infusion procedure. The total concentration of lead in tea samples released $3 \%-19 \%$ into tea infusions. Concentration of lead in green tea products and their infusions and lead percentage release are shown in Table 4 . The calculated average daily intakes of lead from green tea infusions, based on $2 \mathrm{~g}$ of tea in $100 \mathrm{~mL}$ and three cups/day was low for all cases, $\leq 0.002 \mathrm{mg} /$ day and within the bounds of safety ${ }^{10}$ (ATSDR 1999). Average daily intakes of lead from green tea infusions and recommended reference dose are presented in Table 5.

Table 4. Concentration of lead in green tea products and their infusions

\begin{tabular}{cccc}
\hline Sample & $\begin{array}{c}\text { Mean }( \pm \text { RSD }) \\
\mathrm{mg} / \mathrm{kg} \text { (Tea product) }\end{array}$ & $\begin{array}{c}\text { Mean }( \pm \mathrm{RSD}) \\
\mathrm{mg} / \mathrm{kg}(\text { Tea infusion) }\end{array}$ & \% Release \\
\hline Tea 1 & $4.460( \pm 0.758)$ & $0.122( \pm 0.020)$ & 3 \\
Tea 2 & $0.270( \pm 0.046)$ & $0.046( \pm 0.008)$ & 17 \\
Tea 3 & $0.250( \pm 0.043)$ & $0.041( \pm 0.007)$ & 16 \\
Tea 4 & $2.262( \pm 0.385)$ & $0.155( \pm 0.026)$ & 7 \\
Tea 5 & $3.822( \pm 0.650)$ & $0.156( \pm 0.027)$ & 4 \\
Tea 6 & $3.348( \pm 0.569)$ & $0.150( \pm 0.026)$ & 5 \\
Tea 7 & $0.930( \pm 0.158)$ & $0.117( \pm 0.020)$ & 13 \\
Tea 8 & $6.340( \pm 1.078)$ & $0.265( \pm 0.045)$ & 4 \\
Tea 9 & $0.231( \pm 0.039)$ & $0.045( \pm 0.008)$ & 19 \\
\hline \multicolumn{4}{c}{ Calculated as percentage of the total lead amount present in tea powder. }
\end{tabular}


Table 5. Average daily intakes of lead from green tea infusions

\begin{tabular}{|c|c|c|}
\hline Sample & Average daily intakes ${ }^{a}$ & $\begin{array}{c}\text { Daily average intake } \\
\text { for all genders (ATSDR 1999) }\end{array}$ \\
\hline Tea 1 & $0.001 \mathrm{mg} / \mathrm{day}$ & \\
\hline Tea 2 & $<0.001 \mathrm{mg} /$ day & $0.002-0.009 \mathrm{mg} / \mathrm{day}$ \\
\hline Tea 3 & $<0.001 \mathrm{mg} /$ day & \\
\hline Tea 4 & $0.001 \mathrm{mg} /$ day & \\
\hline Tea 5 & $0.001 \mathrm{mg} / \mathrm{day}$ & $0.001 \mathrm{mg} / \mathrm{kg} / \mathrm{day}$ \\
\hline Tea 6 & $0.001 \mathrm{mg} /$ day & \\
\hline Tea 7 & $0.001 \mathrm{mg} / \mathrm{day}$ & \\
\hline Tea 8 & $0.002 \mathrm{mg} / \mathrm{day}$ & $0.001 \mathrm{mg} / \mathrm{kg} / \mathrm{day}$ \\
\hline Tea 9 & $<0.001 \mathrm{mg} /$ day & \\
\hline
\end{tabular}

\section{Conclusion}

The method is accurate, precise and applied successfully for monitoring lead content in some Saudi Arabian marketed green tea products originated from China. The calculated average daily intakes of lead from green tea infusions was low and within the bounds of safety.

\section{Acknowledgment}

Financial support of the King Faisal Specialist Hospital and Research Center is gratefully acknowledged.

\section{References}

1. Fujihara T, Nakagawa-lzumi A, Ozawa T and Numata O, Biotechnol Biochem., 2007, 71, 711.

2. Qin F and Chen W, Environ Contam Toxicol., 2007, 78, 118.

3. Yuan-zhi S, Jian-yun R, Li-feng M, Wen-yan H and Fang W, J Zhejiang Univ Sci., 2008, 9(3), 265.

4. Ansari F, Norbaksh R and Daneshmandirani K, Iran J Environ Health Sci Eng., 2007, 4(4), 243.

5. Needleman H, Апnи Rev Med., 2004, 55, 209.

6. Bellinger D C, Neurotoxicol., 2008, 29, 828.

7. Rowland A S and Mc Kinstry R C, Neurol., 2006, 10, 1464.

8. Sumontha N, Nuchanart R and Jutamaad S, J Agric Food Chem., 2006, 54(18), 6939.

9. Shen F M and Chen H W, Bul Environ Contam Toxicol., 2008, 80(3), 300.

10. Agency for Toxic Substances and Disease Register (ATSDR), Toxicological profile for lead; U.S. Department of Health and Human Services, 1999.

11. PerkinElmer Sciex Instruments, Elan 9000 Inductively coupled plasma mass spectrometer hardware guide, Part Number WE1002729 and software guide, Part Number WE1002821, 2007.

12. Robert T, Practical guide to ICP-MS; Marcel Dekker Inc., NY, USA, 2004. 


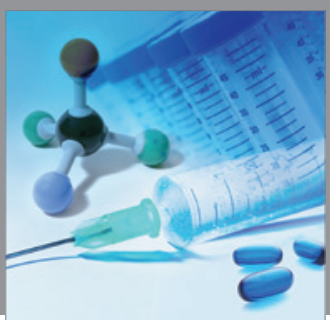

International Journal of

Medicinal Chemistry

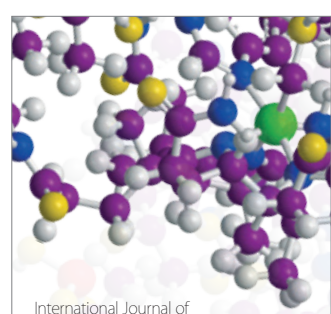

Carbohydrate Chemistry

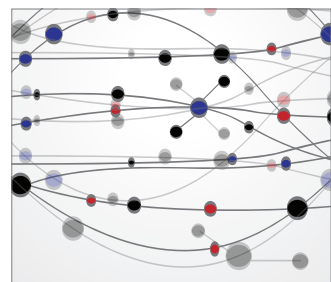

The Scientific World Journal
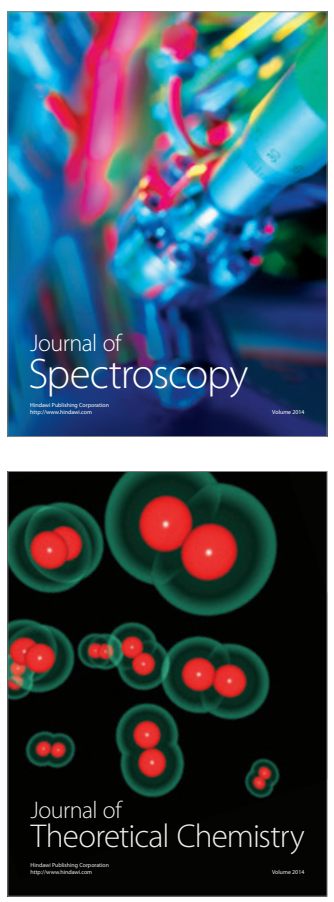
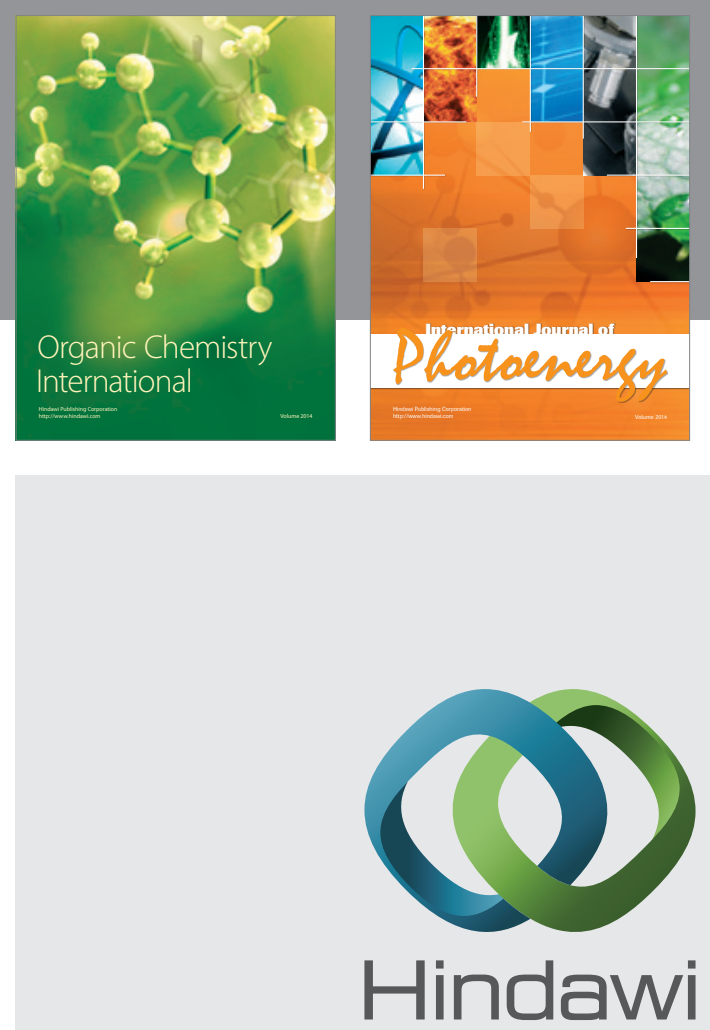

Submit your manuscripts at

http://www.hindawi.com
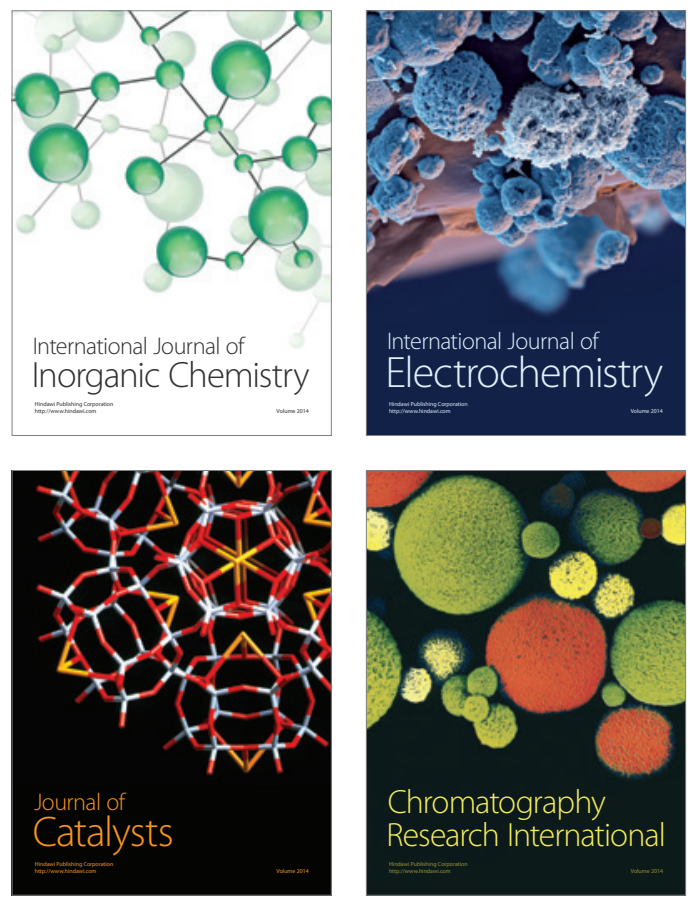
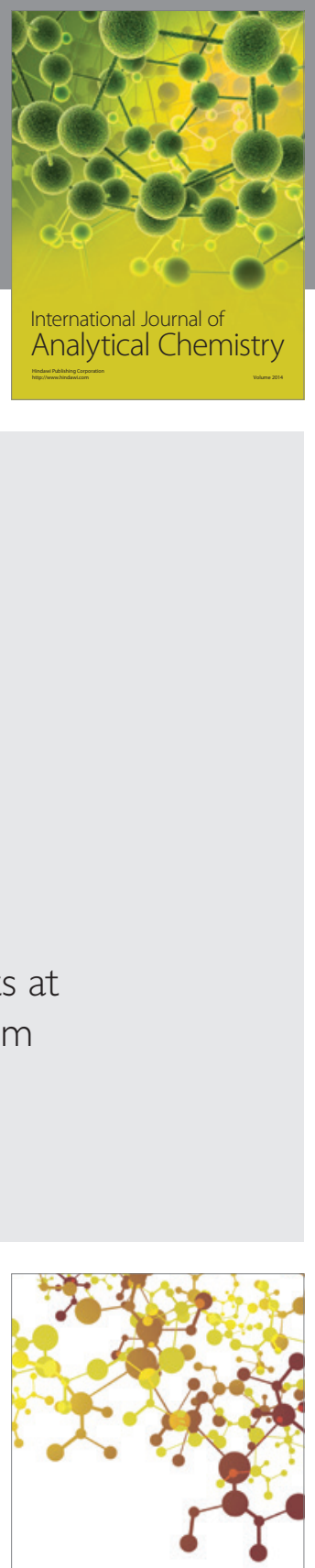

Journal of

Applied Chemistry
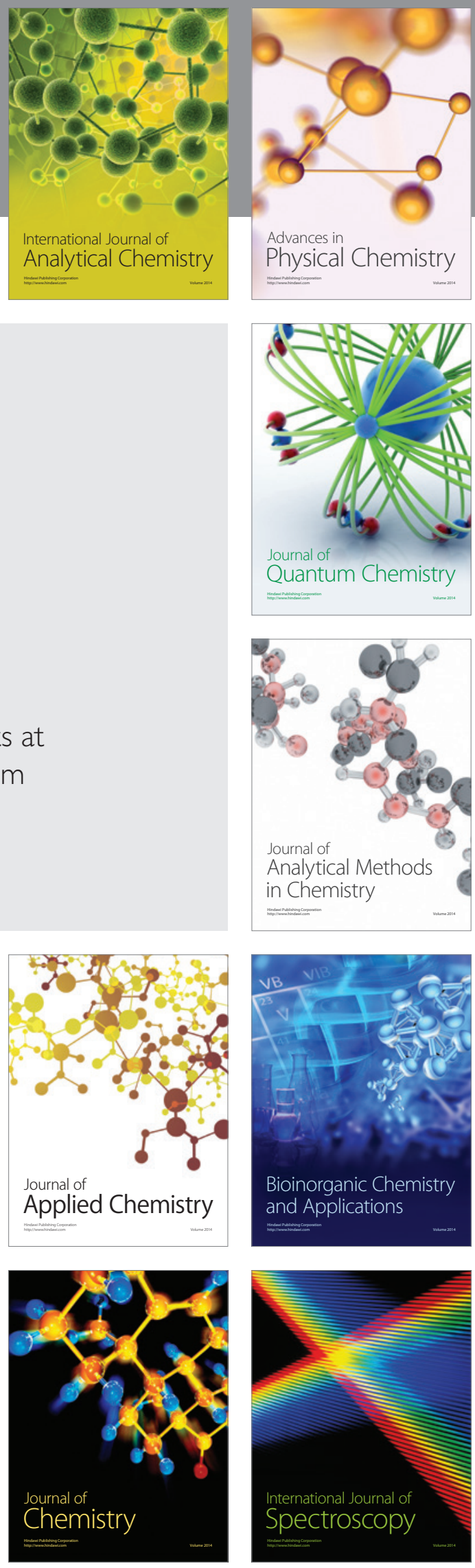